\title{
La atenuante de intoxicación etílica en el proceso penal. Prueba pericial en relación a la misma, y acreditación que exige el Tribunal Supremo. Análisis de una reciente sentencia (T.S. 12/12/2014, Sala Segunda)
}

\author{
JE. Vázquez López \\ Abogado. Sevilla \\ Correspondencia: \\ J. Enrique Vázquez López \\ E-mail: \\ jevazquez@orange.es
}

"¿A qué mal no conduce la embriaguez? Revela los secretos, exagera nuestras esperanzas y nos arroja a la pelea."

Quinto Horacio Flaco (Horacio)

(Venusia, 8 de diciembre de 65 a.C. - Roma, 27 de noviembre de 8 a.C.)
Vivimos en un mundo en constante cambio y profundamente interrelacionado. Hoy más que nunca, resulta evidente que las distancias entre cualquier punto del globo, gracias a los avances de la tecnología aeronáutica, se han reducido hasta hacer que en menos de veinticuatro horas podamos estar en la ciudad del mundo que nos venga en gana. Esto, que en sí mismo es un logro de incalculables consecuencias, provoca que las personas, al relacionarse más y más, necesiten que las normas jurídicas vengan en su auxilio cada vez que haya un problema. De la gravedad y consecuencias de este último, dependerá la norma aplicable. Así, las agresiones que provoquen un grave atentado en la esfera del individuo, sea patrimonial o personal, vienen regidas por el Derecho Penal o Punitivo. En este sentido, el Legislador, siguiendo la tradición que nos viene ya desde Roma, aplica la pena, pero también la individualiza, esto es, la calza directamente al caso y a la persona implicada. Esto conduce ineludiblemente a que exista una serie de causas, tanto de carácter agravante como otras eximentes y atenuantes. Al análisis de una de estas últimas vamos a dedicar estas líneas, dentro, como siempre, de los márgenes que nos concede la propia denominación de esta sección fija.
La atenuante de intoxicación etílica o embriaguez viene recogida, curiosamente, entre las causas de exención de la responsabilidad criminal (Artículo 20.2 del vigente Código Penal), aunque su ámbito de actuación que podemos denominar "natural" es, como hemos dicho, el funcionamiento como atenuante más que como eximente. Así, en la mayoría de los casos resulta relativamente sencillo en la práctica forense acreditar la concurrencia de esta atenuante cuando mediante otras pruebas -atestado policial o testificales, por ejemplo- se viene a tener la certeza de que el culpable vio alterada su voluntad por la ingestión de alcohol. Sin embargo, la anterior afirmación, en el mismo momento en que se plasma en el papel, deviene falsa, y esto requiere cierta explicación.

En efecto, con las pruebas citadas, hay muchas sentencias que sin dudar aplican la atenuante en cuestión. Sin embargo, y en puridad, ¿qué se requiere para que un juez o tribunal deba aplicarla sin duda alguna? 0 lo que es lo mismo, ¿cuáles son los requisitos que a día de la fecha exige nuestro Tribunal Supremo para su indudable aplicación? Pues esta duda vamos a intentar despejarla mediante este acercamiento jurídico que no tiene otra pretensión más que la informativa. 


\section{Antecedentes del caso y primera sentencia}

La Sentencia que vamos a analizar es del Tribunal Supremo, de fecha 12 de diciembre de 2014, y su ponente es D. Juan Ramón Berdugo Gómez de la Torre.

El supuesto es el siguiente, a tenor del relato de hechos declarados probados por la Audiencia Provincial de Jaén, en causa especial con Jurado:

"El acusado Bartolomé, en el mes de junio de 2012 inició en Úbeda una relación de noviazgo con Nieves, comenzando a convivir juntos como pareja de hecho en el mes de septiembre de 2012 en el piso sito en la CI DIRECCIONO00, NUMOOO Portal NUM001 NUM002 de Úbeda, piso que Nieves había alquilado a principios de año a Mateo.

El día 12 de octubre de 2012, el acusado Bartolomé y su pareja Nieves, después de comer en el restaurante "La Estación" de Úbeda, pasaron la tarde en diferentes bares y pubs tanto de Úbeda como de Baeza, consumiendo diversas bebidas alcohólicas como cervezas, vino, combinados de ginebra, así como comiendo distintas tapas y raciones, hasta que sobre las 2.15 horas del día 13 de octubre de 2012 llegaron al pub "Bandana" de Úbeda, donde igualmente consumieron dos combinados de ginebra y donde iniciaron una discusión motivada porque Nieves había mantenido una conversación a solas con Luis Antonio, propietario del pub, y con quien, al parecer, había mantenido anteriormente una relación íntima.

Sobre las 2.45 horas del referido día 13 de octubre de 2012, tras abandonar el pub "Bardana" se dirigieron, sin cesar durante el trayecto la discusión anteriormente iniciada, al domicilio de ambos sito en la Ci DIRECCIONOOO , NUMOOO Portal NUMOO1 NUM002 de Úbeda, donde continuaron discutiendo hasta que al decirle Nieves al acusado, al parecer, que ya no lo quería, que se marchara de la casa porque estaba esperando a Luis Antonio, el acusado le propinó diversos y fuertes golpes a Nieves en la cabeza, en la cara, en el cuello y en el tórax, lo que hizo que Nieves perdiera la conciencia y cayera al suelo, y una vez caída en el suelo boca arriba e inconsciente, el acusado, con la intención de causarle la muerte y sin que Nieves tuviera posibilidad alguna de defenderse, se situó encima de ella y con las manos apretó fuertemente el cuello de Nieves hasta que le produjo la muerte por asfixia.

Una vez muerta, el acusado, con el fin de ocultar los hechos que acababa de realizar, prendió fuego de forma deliberada a un sillón o sofá existente en el salón del piso, situado junto al cadáver de Nieves, cerró las persianas, así como la puerta del salón, y tras cerrar igualmente con llave la puerta de entrada al piso se marchó utilizando el vehículo de Nieves en dirección a la población de GüejarSierra, Granada, domicilio de su padre, si bien fue detenido por la Guardia Civil poco antes de llegar a la misma al haber tenido un accidente por salida de la vía y posteriormente manifestar que había dado una paliza a su novia y reconoció los hechos.

El fuego iniciado por el acusado se extendió rápidamente por el salón afectando al mobiliario del mismo, a los falsos techos de escayola del salón que cedieron por los efectos del calor, y el cadáver de Nieves quedó parcialmente carbonizado, extendiéndose el humo por el resto del piso y llegando a salir al rellano de la escalera, lo que hizo que Julián y María Consuelo, vecinos colindantes del piso de Nieves y el acusado, tuvieran que huir rápidamente con su hijo menor de edad, atemorizados ante el peligro que suponía para sus vidas, y que avisaran a los bomberos que procedieron, tras el desalojo de los demás vecinos, a la extinción del incendio.

Los daños causados como consecuencia del incendio han sido tasados en 14.328 euros los causados al mobiliario, en 30.047,40 euros los causados al inmueble, y 1.067,89 euros derivados del servicio de extinción de incendios."

Los hechos anteriores determinaron la siguiente parte dispositiva en primera instancia:

"FALLO.- "Que debo condenar y condeno a Bartolomé, como autor criminalmente responsable del delito de asesinato ya definido, con la concurrencia de la circunstancia agravante mixta de parentesco, a la pena de dieciocho años de prisión, con la concurrencia de inhabilitación absoluta durante el tiempo de la condena.

Que debo condenar y condeno a Bartolomé como autor civilmente responsable del calificado delito de incendio, a la pena de prisión de cinco años menos un día, con las accesorias de inhabilitación especial para el ejercicio del derecho de sufragio pasivo durante el tiempo de la condena.

Que debo condenar y condeno a Bartolomé a que abone en concepto de Responsabilidades Civiles a que indemnice a D. Juan Miguel y a Celestina en la cantidad de 200.000 euros, a D. Mateo en la cantidad de 44.375,40 euros y al Ayuntamiento de (tecla en la cantidad de 1.067,89 euros, cantidades que se incrementarán en los intereses legales previstos en el $n^{\circ} 576$ de la Ley de Enjuiciamiento Civil, desde la firmeza de la presente resolución. 
Con imposición de las costas a Bartolomé, incluidas las de las acusaciones particulares."

\section{Recurso de apelación}

La anterior Sentencia fue recurrida, tanto por las acusaciones como por la defensa del acusado, recayendo nueva resolución por la Sala de lo Civil y de lo Penal del Tribunal Superior de Justicia de Andalucía, del siguiente tenor literal:

"Que estimando parcialmente el recurso de apelación formulado por la defensa de Bartolomé contra la sentencia dictada por el IImo. Sr. MagistradoPresidente del Tribunal del Jurado, en el ámbito de la Ilma. Audiencia Provincial de Jaén (Sección Segunda), en causa seguida por delito de asesinato e incendio, debe revocar y revoca la referida resoIución en el sentido de absolver a Bartolomé del delito de asesinato por el que venía condenado, y condenarlo como autor de un delito de homicidio doloso con las circunstancias agravantes de parentesco y atenuante de intoxicación etílica, a la pena de trece años y seis meses de prisión, con la accesoria de inhabilitación absoluta durante el tiempo de condena; y apreciando también respecto del delito de incendio por el que viene condenado, la circunstancia atenuante de intoxicación etílica, aunque manteniendo las penas impuestas por tal delito. Con confirmación del resto de los pronunciamientos de la sentencia y sin condena al pago de las costas de esta alzada."

(Las negritas son del autor).

\section{Recurso de casación y nueva sentencia}

Contra la anterior resolución se plantearon respectivos recursos, tanto por las acusaciones como por parte de la defensa del acusado. En este sentido, su representación procesal se basó en varios motivos casacionales, uno de los cuales tendía a solicitar la apreciación de otra atenuante, concretamente la de arrebato u obcecación (también denominada de estado pasional), aparte de otros reproches jurídicos que se desestimaron en su totalidad.

Las acusaciones plantearon casación, con el motivo fundamental de que no se aplicara la atenuante de intoxicación etílica estimada por el T.S.J.A. en la segunda instancia.
Por lo que respecta a la atenuante de arrebato u obcecación alegada por la defensa del acusado, el Alto Tribunal, después de realizar un somero análisis de los requisitos exigidos para la apreciación de dicha atenuante en cada caso concreto, concluye que "no cualquier estímulo es válido a los efectos de atenuar la responsabilidad por la vía de la atenuante de estado pasional". Es más, continúa la Sentencia haciendo referencia a otra que compendia la doctrina de la Sala, afirmando que “... tal estado pasional tiene que tener una intensidad suficiente para romper los mecanismos inhibitorios, de modo que el sujeto se encuentre inmerso en una situación emotiva que la ley ha denominado como de "arrebato" u "obcecación"."

Así, y tras repasar la doctrina referida, vuelve la Sentencia al relato de hechos fácticos declarados probados para comprobar si realmente se dan los requisitos necesarios para estimar el reproche alegado en casación, y se concluye que "Asimismo declaró probado, también por unanimidad -en el apartado /IH-causas de exención o atenuación de responsabilidad-que el acusado al cometer los hechos no tenía alteradas sus facultades intelectivas y volitivas como consecuencia de la discusión previa que mantuvo con la víctima, y consecuente con ello no declaró probado, por unanimidad, las proposiciones $E, F y$ $G$, relativas a la anulación, afectación de manera importante y afectación leve de aquellas facultades como consecuencia de esa previa disensión.

Siendo así la no apreciación de la atenuante cuestionada debe ser mantenida, por cuanto solo está acreditada esa discusión entre agresión y víctima iniciada en el último pub y que continuó en el piso, discusión airada si se quiere, pero que no puede ser considerada suficiente para configurar la atenuante de arrebato.

Las referencias que en el motivo se contienen al consumo excesivo de bebidas alcohólicas constituyen el presupuesto de la estimación por la sentencia recurrida -la dictada por el Tribunal Superior de Justicia-de la atenuante analógica de embriaguez, pero no pueden servir de base para la apreciación de la atenuante de arrebato, esto supondría encontrarnos ante una doble valoración del mismo hecho, proscrita por el art. 67 CP."

(Las negritas son del autor).

De este modo, y con total respeto al relato de hechos declarados probados, la Sentencia dictamina no aplicable la atenuante pasional alegada, sirviéndonos los pasajes recogidos de manera literal a los efectos que dentro de poco vamos a abordar. Por ello, el Tribunal 
Supremo ya de manera sutil anuncia su intención de respetar los hechos probados declarados como tales por el Tribunal del Jurado, respeto que necesariamente tendrá las consecuencias que más adelante expondremos, motivo más que suficiente como para habernos detenido siquiera un poco en la resolución de otra atenuante que podía tener la misma fundamentación que la de intoxicación etílica.

Por ello, y pasando un poco por alto el resto de la argumentación de la resolución que ahora traemos a colación -el texto de la Sentencia tiene 25 páginas-, entramos de lleno en el debate sobre la aplicación o no de la atenuante de intoxicación etílica apreciada en segunda instancia y discutida en casación. A este respecto, las acusaciones-recurrentes habían alegado que la atenuación por consumo de alcohol exige no solo la acreditación de la ingesta, sino también que se acredite la influencia de dicho consumo sobre las condiciones de imputabilidad del agente.

$Y$ en este sentido, el Alto Tribunal coincide con la tesis mantenida por las acusaciones, estableciendo textualmente que "se ha de partir necesariamente de que no basta el consumo de bebidas alcohólicas para que se entienda siempre disminuida la imputabilidad y la responsabilidad penal del sujeto; por ello, cuando se trata de la ingesta de bebidas alcohólicas es necesario determinar de alguna forma no solo los líquidos ingeridos o al menos la existencia del consumo junto con datos que permitan su valoración, sino además precisar suficientemente los efectos que ha causado en la capacidad del sujeto para entender la ilicitud del hecho o para actuar conforme a esa comprensión (STS. 1424/2005 de 5.12), y en este sentido es particularmente útil acudir a la conducta del sujeto no solo en relación a los concretos hechos constitutivos del delito, sino también a todos aquellos otros periféricos al mismo que pueden aportar datos sobre su estado (STS. 631/2004 de 13.5). La influencia de la embriaguez debe ser de tal intensidad que anula considerablemente la capacidad de comprender la ilicitud del hecho o de actuar conforme a esa comprensión.

No es, desde luego, un resorte automático para dulcificar la necesidad de la pena, en todo caso (STS. 136/2007 de 8.2).

En el caso presente, la sentencia del Tribunal Superior de Justicia no procede a examinar el relato de hechos probados - que al no considerar probadas por unanimidad las proposiciones // $A, B$ y $C$, y sí probada la $D$ - no contiene referencia alguna a que el consumo de bebidas alcohólicas hubiese afectado a las facultades 23 volitivas e intelectivas del acusado, sino que realiza una nueva valoración de la prueba y sustituyendo la realizada por el Tribunal de Jurado considera que Bartolomé tenía tales facultades alteradas, basándose en el informe pericial de Doña Eloisa y Faustino, efectuado el 8.1.2013, sobre la base de "los documentos obrantes en las diligencias" en el que se dice que Bartolomé consumió en aqueIla jornada, en diversos lugares, y a lo largo de unas doce horas, un Martín blanco, cuatro vinos blancos, otras seis o siete copas de vino y cinco combinados de tónica con ginebra, y en que cuatro horas después de los hechos el acusado fue sometido a una prueba de alcohol (Drage alcotest 7110 E) y el resultado fue de 0,48 mg/l y 0,51 mg/l, y que en el cadáver de la víctima se apreció 1,65 $\pm 0,08 \mathrm{mg} / \mathrm{l}$ de alcohol etílico, para concluir que conforme a las reglas de la experiencia la ingesta de una gran cantidad de alcohol comporta al menos la afectación de la facultad de autocontrol, por cuanto, sobre la base de la gran ingesta de alcohol, lo razonable es tener por acreditada la merma de facultades a menos que se hubieran aportado pruebas que evidenciasen un comportamiento normal en el momento de los hechos, para seguidamente analizar determinadas manifestaciones de testigos, y estimar el motivo de apelación y apreciar la concurrencia de la atenuante analogía de embriaguez.

Razonamiento de la Sala de apelación, sustituyendo la valoración realizada por el Jurado que no puede ser compartido."

(Las negritas siguen siendo del autor).

Así, el Supremo anticipa ya que va a casar la Sentencia por lo que se refiere a la atenuante mal aplicada, y lo hace fundamentalmente atendiendo a dos motivos básicos:

A. Porque la Sentencia de segunda instancia no respetó el relato de hechos probados que aprobó el Jurado.

B. No basta acreditar el consumo de alcohol, sino que habría que acreditar la afectación que produce en el sujeto y su grado de imputabilidad.

En efecto, aunque no se discute por ninguna de las partes que el día de los hechos el acusado ingirió abundantes bebidas alcohólicas, no consta prueba suficiente de que dicha ingesta fuera de una entidad suficiente para afectar la voluntad, lo cual casa perfectamente con la prueba de alcoholemia que se realizó, y aunque la muestra se tomó cuatro horas después de ocurrir los hechos, sigue sin acreditar una merma de facultades que hemos de remitir al momento de ocurrir el crimen, y no antes ni después.

Por todo lo anterior, el Tribunal entiende que la prueba existente revela que el acusado no tenía afectadas 
sus facultades, con base en los siguientes datos que constan en las diligencias:

A. Los agentes de la Guardia Civil que practicaron la prueba de alcoholemia no le notaron -al acusado- síntomas externos de haber bebido.

B. El resto de testigos tampoco apreció síntomas de embriaguez en el acusado el día de los hechos.

C. La propia conducta desarrollada por el acusado después de cometer los hechos revela que, pese al alcohol ingerido, no tenía afectadas sus capacidades intelectivas y volitivas, ya que prende fuego a un sillón con la finalidad de ocultar los hechos, y fue capaz de conducir su vehículo de noche durante varias horas, efectuando incluso varias Ilamadas telefónicas.

\section{Especial referencia a la prueba pericial}

El Tribunal Supremo, en uno de los motivos casacionales alegados por la defensa, ha de detenerse para reiterar su propia doctrina en cuanto a la prueba pericial -médica en este caso- a efectos del recurso de casación, entendiendo que los informes forenses y la prueba en sí no son en realidad documentos en términos estrictos, sino pruebas personales documentadas consistentes en pareceres técnicos sobre determinadas materias por parte de quienes tienen una preparación especial, con la finalidad de facilitar al Tribunal su labor a la hora de valorar la prueba.

Así, la Sentencia establece lo siguiente al respecto: "Por ello la Sala Segunda solo excepcionalmente ha admitido la virtualidad de la prueba pericial como fundamentación de la pretensión de modificación del apartado fáctico de una sentencia, impugnada en casación, en supuestos como:

a. existiendo un solo dictamen o varios absolutamente coincidentes y no disponiendo la Audiencia de otras pruebas sobre los mismos elementos fácticos, el Tribunal haya estimado el dictamen o dictámenes coincidentes como base única de los hechos declarados probados, pero incorporándolos a dicha declaración de un modo incompleto, fragmentario, mutilado o contradictorio, de forma que se altere relevantemente su sentido originario.

b. cuando contando solamente con dicho dictamen o dictámenes coincidentes y no concurriendo otras pruebas sobre el mismo punto fáctico, el Tribunal de instancia haya llegado a conclusiones divergentes con las de los citados informes, sin expresar las razones que lo justifiquen o sin una explicación razonable (SSTS. 9182/2000 de $8.2,1224 / 2000$ de $8.7,1572 / 2000$ de $17.10,1729 / 2003$ de 24.12, 299/2004 de 4.3, 417/2004 de 29.3).

Y una vez ratificada la propia doctrina, que resulta como vemos consolidada, entra el Tribunal a analizar la prueba pericial practicada al caso, con el siguiente comentario:

"En el caso analizado el recurrente destaca cómo los médicos forenses Sra. Eloísa y Sr. Faustino efectuaron el informe de valoración de imputabilidad de 12.11.2012, informe en el que se hace constar que no se les facilitan las diligencias, basado en una exploración que se efectúa a Bartolomé en la Clínica Forense de Jaén el 25.10.2012, es decir, 13 días después de los hechos y en él se concluye que “... el explorado en el momento actual conserva íntegras sus capacidades intelectiva y volitivas, sin que detecte alteración psicopatológica alguna... comprende la diferencia entre lo lícito y lo ilícito, y conserva íntegra su capacidad actual según esta comprensión... el día de autos, refiere haber ingerido gran cantidad de bebidas alcohólicas. El consumo de gran cantidad de alcohol puede llevar a un estado de embriaguez, susceptible de producir merma en la capacidad de comprender y de actuar conforme a tal compresión. No obstante, no podemos pronunciarnos en cuanto a esa merma ya que desconocemos el grado de impregnación alcohólica...".

$Y$ en el Informe Forense complementario de 8.1.2013, para el que ya se facilita a los forenses documentación obrante en autos, con respecto al supuesto consumo de Bartolomé el día que suceden los hechos, se sienta que “... El día de autos, se constata que ingiere gran cantidad de bebidas alcohólicas... pero... se puede estimar el grado de alcoholemia que sufrió el imputado en el momento de los hechos...".

Por lo tanto, de esos informes lo único que los forenses afirman y concluyen es que el día 25.12.2012, es decir, 13 días después de los hechos, y no al tiempo de la comisión de estos, Bartolomé tenía integras sus capacidades intelectivas y volitivas. Conclusión que es la misma que mantuvieron los citados forenses en el juicio oral en el que manifestaron "... que le hicieron (en la exploración del 25 de octubre) a Bartolomé una serie de preguntas, estudiaron su historia clínica y con estos antecedentes hicieron sus conclusiones, según las cuales sabe y conoce lo que hace y que no estaba afectado por nada; que distingue lo lícito y lo ilícito, lo que está bien y lo que está mal...". 
(En este caso, las negritas son de la propia Sentencia comentada).

Una vez realizados los anteriores comentarios, la Sala desestima las alegaciones esgrimidas por la defensa. No obstante, y como ya se ha dicho, resulta de interés al caso reflejar de nuevo la doctrina antedicha, y las precisiones realizadas por los forenses que reconocieron al acusado, a los efectos del mejor conocimiento del caso.

\section{Conclusión}

En la nueva Sentencia, el Supremo casa y anula la anterior, declarando haber lugar parcialmente a los recursos de casación interpuestos por la acusación particular y la Junta de Andalucía, dictando nueva resolución con el siguiente fallo:

"Manteniendo el resto de los pronunciamientos de la sentencia dictada por el Tribunal Superior de Justicia de Andalucía de 5 de mayo de 2014, debemos condenar y condenamos a Bartolomé como autor responsable de un delito de homicidio con la agravante de parentesco a la pena de 14 años y 6 meses, con inhabilitación absoluta durante el tiempo de la condena."

Así, elimina cualquier referencia a la atenuante de intoxicación etílica, apreciada en su momento por el T.S.J.A.
En resumidas cuentas, la moraleja que podríamos obtener del caso viene a avalar el aforismo jurídico que establece que "En Derecho, todo hay que probarlo y nada darse por supuesto", en el sentido de que aunque nos encontremos en sede penal y no podamos lógicamente apreciar elementos en contra del acusado sin una prueba plena, del mismo modo hemos de exigir que cualquier circunstancia que pueda beneficiar al reo -como una atenuante o eximente, por ejemplo- ha de quedar cumplidamente demostrada si no queremos quebrar el sistema por desigualdad de armas para las partes, y por un consecuente deterioro de la Justicia material en definitiva.

Además, hay otra conclusión que sin ningún esfuerzo llega a nuestra mente después del análisis realizado, y es la de que no podemos modificar la "santidad" de los hechos declarados probados sin tener razones de mucho peso para ello, debiendo en todo caso motivar escrupulosamente cualquier modificación de los mismos. Ello redunda en beneficio de la seguridad jurídica, y de un principio elemental del derecho que defiende la no indefensión, pueda parecer o no esta misma frase una curiosa paradoja.

Y es que, como nos dice Horacio al principio de estas líneas, mal vamos si nos dejamos influir por sustancias que enturbien nuestro entendimiento. Por ello, tengámoslo siempre a punto para no perjudicar al débil, y hacer justicia al que la pide. Y esto último, como tantas otras verdades, puede aplicarse tanto a la Roma de hace 2.000 años como a nuestros días. 